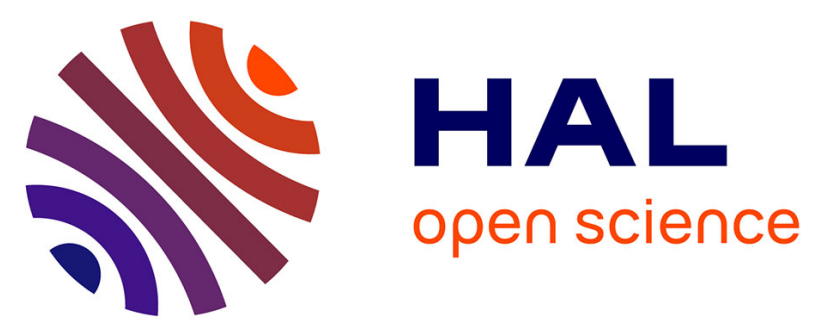

\title{
Prospective association between adherence to the 2017 French dietary guidelines and risk of death, CVD and cancer in the NutriNet-Santé cohort
}

Dan Chaltiel, Chantal Julia, Raphaël Chaltiel, Julia Baudry, Mathilde Touvier, Valérie Deschamps, Paule Latino-Martel, Léopold K Fezeu, Serge Hercberg, Emmanuelle Kesse-Guyot

\section{To cite this version:}

Dan Chaltiel, Chantal Julia, Raphaël Chaltiel, Julia Baudry, Mathilde Touvier, et al.. Prospective association between adherence to the 2017 French dietary guidelines and risk of death, CVD and cancer in the NutriNet-Santé cohort. British Journal of Nutrition, 2022, 127 (4), pp.619-629. 10.1017/s0007114521001367 . hal-03238351

\section{HAL Id: hal-03238351 https://hal.inrae.fr/hal-03238351}

Submitted on 27 May 2021

HAL is a multi-disciplinary open access archive for the deposit and dissemination of scientific research documents, whether they are published or not. The documents may come from teaching and research institutions in France or abroad, or from public or private research centers.
L'archive ouverte pluridisciplinaire HAL, est destinée au dépôt et à la diffusion de documents scientifiques de niveau recherche, publiés ou non, émanant des établissements d'enseignement et de recherche français ou étrangers, des laboratoires publics ou privés. 


\section{Prospective association between adherence to the 2017 French dietary guidelines and risk of death, cardiovascular diseases, and cancer in the NutriNet-Santé cohort}

Dan Chaltiel ${ }^{1}$, Chantal Julia ${ }^{1,2}$, Raphaël Chaltiel $^{3}$, Julia Baudry ${ }^{1}$, Mathilde Touvier ${ }^{1}$, Valérie Deschamps $^{4}$, Paule Latino-Martel ${ }^{1}$, Léopold K. Fezeu ${ }^{1,2}$, Serge Hercberg ${ }^{1,2}$, Emmanuelle KesseGuyot $^{1}$

${ }^{1}$ Sorbonne Paris Nord University, Inserm, INRAE, Cnam, Nutritional Epidemiology Research Team (EREN), Epidemiology and Statistics Research Center - University of Paris (CRESS), 93017 Bobigny, France

${ }^{2}$ Public Health Department, Avicenne Hospital, AP-HP, Bobigny, France

${ }^{3}$ Jean Godinot Cancerology Institute, Reims, France

${ }^{4}$ Nutritional Surveillance and Epidemiology Team (ESEN), French Public Health Agency, Paris-13 University, Centre de recherche en épidémiologie et statistiques, COMUE Sorbonne Paris Cité, Bobigny, France

PubMed indexing: Chaltiel, Julia, Chaltiel, Baudry, Touvier, Deschamps, Latino-Martel, Fezeu, Hercberg, Kesse-Guyot

\section{Corresponding author:}

Emmanuelle KESSE-GUYOT

Equipe de Recherche en Epidémiologie Nutritionnelle (EREN)

SMBH Sorbonne Paris Nord

74 rue Marcel Cachin, 93017 Bobigny, France

Tel: +33148388963

Fax: +3314838 8931

E-mail: e.kesse@eren.smbh.univ-paris13.fr

Running head: French dietary guidelines and cancer, cardiovascular diseases and death

Words count: abstract $=308$, text $=3819$

Number of tables: $4+4$

Number of figures: 1

Keywords: nutrition, dietary index, adherence, guidelines, risk, cancer, cardiovascular diseases, death

\section{Abbreviations:}

NCD: Non-communicable diseases

CVD: cardiovascular diseases

PNNS: French Nutrition and Health Program (Programme National Nutrition Santé)

PNNS-GS2: PNNS Guidelines Score 2

mPNNS-GS: modified PNNS-GS

FBDG: food-based dietary guidelines 
HEI: Healthy Eating Index

AHEI-2010: Alternate HEI, version 2010

MDS: Mediterranean Diet Score

$\mathrm{CU}$ : consumption unit

ICD-10: international classification of diseases, 10th revision

IPAQ: International Physical Activity Questionnaire

CDQI: cancer specific diet quality index 


\section{Abstract}

1 Background: Non-communicable diseases, such as cancers and cardiovascular diseases (CVD), 2 represent a major public health concern and diet is an important factor in their development. French 3 dietary recommendations were updated in 2017 and an adherence score, the PNNS-GS2, has been 4 developed and validated using a standardised procedure. This study aimed to analyze the prospective 5 association between PNNS-GS2 and the risk of death, cancer and CVD.

6 Methods: Our sample consisted of French adults included in the prospective NutriNet-Santé cohort $7 \quad(\mathrm{~N}=67,748, \mathrm{~N}=75,634$, and $\mathrm{N}=80,269$ for the risk of death, cancer, and CVD respectively). PNNS8 GS2 (range: $-\infty$ to 14.25) was calculated from the 24-hour dietary records of the first 2 years of 9 monitoring. Association between PNNS-GS2 (in quintiles, Q) and risk of death, cancer and CVD was 10 studied using Cox models adjusted for the main confounding factors.

11 Results: The sample included 78\% of women, aged on average 44.4 years ( $\mathrm{SD}=14.6)$ with on average $126.6(\mathrm{SD}=2.3)$ dietary records. Average PNNS-GS2 was $1.5(\mathrm{SD}=3.4)$ and median follow-up was 6.6 13 years for cancers and 6.2 years for CVD and deaths. PNNS-GS2 was significantly associated with the 14 risk of death ( $\mathrm{HR}_{\mathrm{Q} 5 \mathrm{vs} \mathrm{Q}_{1}[\mathrm{CI} 95 \%]}=0.77[0.60-1.00], 828$ cases$)$, cancer $\left(\mathrm{HR}_{\mathrm{Q} 5 \mathrm{vs} \mathrm{Q}}=0.80[0.69-0.92], 2,577\right.$ 15 cases), and CVD (HR ${ }_{\mathrm{Q} 5 \mathrm{vQ}}=0.64[0.51-0.81], 964$ cases). More specifically, PNNS-GS2 was 16 significantly associated with colorectal and breast cancer risks but not prostate cancer risk.

17 Conclusion: Our results suggest that strong adherence to the 2017 French dietary recommendations is 18 associated with a lower risk of death, cancer or CVD. This reinforces the validity of these new 19 recommendations and will help to promote their dissemination. 


\section{Introduction}

21 In almost all countries, the burden of non-communicable diseases (NCD) is a major public health 22 concern. Indeed, in 2016, according to the WHO, the mortality due to NCD was $71 \%$ worldwide, and

23 up to $88 \%$ in high-income countries such as France, where cardiovascular diseases (CVD) and cancers 24 represent the largest causes of death ${ }^{1}$.

25 As NCDs induce a high mortality and social burden, the challenge is to develop preventive measures 26 by acting on modifiable risk factors such as dietary habits. As a matter of fact, there is growing 27 recognition of the importance of diet, among other lifestyle factors, in the development of cancer and $28 \mathrm{CVD}^{2}$.

29 "Optimal" diet is not absolute and most countries, which differ on culture and ethnicity, have each 30 their own definition of a favorable diet and translate them into easily understandable food-based 31 dietary guidelines (FBDG) ${ }^{3}$. However, there is a growing consensus on which food groups should be 32 promoted or limited in order to minimize the risk of NCD, and most guidelines recommend high 33 consumption of fruits, vegetables and wholegrains and low intake of meats, fats, sugary and salted 34 foods $^{3}$.

35 When assessing the association between overall diet quality and health outcomes, many studies use 36 dietary quality scores, such as the Healthy Eating Index or the Mediterranean Diet Score ${ }^{4-7}$ but also 37 specific dietary guidelines developed in European countries such as Denmark ${ }^{8}$, $\mathrm{UK}^{9}$ and Netherland ${ }^{10}$. 38 Some of these have been recently compared in a modelling study ${ }^{11}$.Indeed, considering dietary 39 exposure through scores allows to consider diet as a whole, accounting for complex synergies between 40 foods and nutrients, which is considered closer to reality as foods are not consumed in isolation ${ }^{12-15}$.

41 When a diet quality score is based on official guidelines, studying its association with health outcomes 42 also allows assessing the relevance of the guidelines regarding the prevention of these outcomes.

43 In France, FBDG were revised in March $2017^{16}$ as a core part of the $4^{\text {th }}(2019-2023)$ French Nutrition 44 and Health Program (Programme National Nutrition Santé, "PNNS"). Recently, we developed and 45 validated the PNNS-Guidelines Score 2 (PNNS-GS2), aiming to estimate the adherence to the 2017 46 FBDG $^{17}$. The PNNS-GS2 was meant to update the PNNS-GS, based on 2001 guidelines, which were 47 less specific, less plant-based and did not consider organic food. 
48 Hence, the present study aimed at assessing the prospective associations between the PNNS-GS2 and

49 risk of non-accidental mortality, cardiovascular disease mortality or incidence and cancer mortality or

50 incidence in a large French prospective cohort. In particular, the role of adjustment on BMI was

51 assessed as we previously showed that the PNNS-GS2 is highly associated with the risk of overweight

52 and obesity ${ }^{18}$, which are themselves major risk factors for cancer and $\mathrm{CVD}^{19-21}$.

\section{Subjects and Methods}

\section{Study population}

55 The data were collected in the NutriNet-Santé cohort, a large observational prospective web-based 56 cohort launched in 2009 in France. Its purpose is to investigate the associations between nutrition and 57 health, as well as determinants of dietary behavior and nutritional status. The detailed design and 58 methodology have been described elsewhere ${ }^{22}$. Participants were recruited through vast multimedia 59 campaigns, amongst the adult ( $>18$ years old) population having access to the internet. All 60 questionnaires were pilot-tested and completed online using a dedicated website (www.etude-nutrinet61 sante.fr). The NutriNet-Santé study is conducted in accordance with the Declaration of Helsinki and 62 was approved by the ethics committee of the French Institute for Health and Medical Research (IRB 63 Inserm no. 0000388FWA00005831) and by the National Commission on Informatics and Liberty 64 (CNIL no. 908450 and no. 909216). Electronic informed consent was obtained from all participants. 65 The NutriNet-Santé study is registered in ClinicalTrials.gov (NCT03335644).

\section{Dietary data}

67 Participants are asked to provide three non-consecutive $24 \mathrm{~h}$ dietary records assigned over a 2-week 68 period at baseline then twice a year. Days are randomly attributed into two weekdays and one weekend 69 day to account for intra-individual variability in intake. All food and drink consumption throughout 70 the entire day (midnight to midnight) are recorded by participants via the dedicated online platform 71 providing a food browser (grouped by category) or a search engine. Participants declare intakes as 72 absolute units when known (in $\mathrm{g}$ or $\mathrm{mL}$ ), common household measures or using food portion size from 73 validated pictures ${ }^{23}$.

74 Intakes were weighted according to weekday vs. weekend day and daily energy and nutrient intakes 75 were computed using a validated and constantly updated composition tables including more than 3,500 
76 food items ${ }^{24}$. Under-reporters were excluded using the published method by Black et al. with Goldberg

77 cut-offs, which is based on physical activity level (PAL) and basal metabolic rate (BMR). BMR was

78 calculated using the Schofield's equations ${ }^{25}$, accounting for gender, age, height and weight. Withinsubject variation coefficient (day-to-day ) for energy intake was calculated individually for each

80 participant based on their $24 \mathrm{~h}$ dietary records data and within-subject coefficients of variations for 81 BMR and PAL were defined at $8.5 \%$ and $15 \%$ respectively ${ }^{26,27}$. This dietary recording protocol has 82 been tested and validated against an interview by a trained dietitian and against blood and urinary 83 biomarkers ${ }^{28-30}$.

84 Frequency of organic food consumption was assessed within 2 months after inclusion for fruits, 85 vegetables, bread, and starchy foods (rice, pasta and legumes) using a previously described 86 questionnaire ${ }^{17,31}$. Frequencies were assessed using three modalities of consumption: (1) most of the 87 time; (2) occasionally; (3) never. Concerning starchy foods, the frequency of organic food consumption was considered twice, once for rice and pasta and once for legumes, but each item was

89 considered null if it was not reported as consumed in the 24-hour dietary records.

\section{Computation of dietary scores}

91 The PNNS-GS2 is a dietary index (theoretical range $=[-17 ; 13.5]$ ) designed to reflect the adherence to 92 the 2017 French FBDG ${ }^{16,32}$. It includes 13 components, 6 of adequacy and 7 of moderation, and is 93 penalized on energy intake in such a way that if a participant has an energy intake higher than $105 \%$ 94 of the energy expenditure, the score is reduced by the same ratio. Its components, scorings and weights 95 are presented in Table 1.

\section{Case ascertainment}

97 Participants self-declared health events through the health status questionnaire every three months, or at any time using a specific interface on a secured dedicated website.

99 For each incident disease declared, a physician from the study team contacted the participant and asked 100 to provide any relevant medical records (e.g., diagnoses, hospital admissions, radiological reports, 101 electrocardiograms). If necessary, the study physicians could contact the patient's physician or 102 hospitals to collect additional information. Afterwards, a committee of physicians reviewed all medical 103 data to validate major health events. Participants' families or doctors, based on data previously 104 provided by the participants, were contacted when there had been no response to the study website for 
more than one year. This process constituted the main source of case ascertainment in the cohort. In addition, our research team was the first in France authorized by the Council of State (No 2013-175) to link data from our general population-based cohorts to medico-administrative databases of national health insurance (SNIIRAM). This data collection has helped us to limit the potential bias from those

109 who had not reported their health events to the study investigators.

110 We also used linkage to the French national cause-specific mortality registry (CépiDC) to detect deaths 111 and potentially missed cases for deceased participants. We classified cancer and CVD cases by using 112 the international classification of diseases, 10th revision (ICD-10). In this study, we considered all first 113 primary cancers diagnosed between the inclusion date and 13th May, 2019 to be cases, except for basal 114 cell skin carcinoma which we did not consider as cancer. For CVD, we focused on first incident cases 115 of stroke (I64), myocardial infarction (I21), acute coronary syndrome (I20.0 and I21.4), and 116 angioplasty (Z95.8).

\section{Covariates}

118 Using a dedicated self-administered web-based questionnaire ${ }^{22}$, participants filled in their 119 sociodemographic and lifestyle characteristics (age, sex, education, occupation, income, marital status, 120 physical activity and smoking habits). Physical activity was assessed by the International Physical 121 Activity Questionnaire (IPAQ) ${ }^{33}$. Monthly income was estimated per consumption unit according to a 122 weighting system, where one consumption unit (cu) is attributed for the first adult in the household, $1230.5 \mathrm{CU}$ for other persons aged 14 or older, and $0.3 \mathrm{cu}$ for children under $14^{34}$. Baseline height and 124 weight were self-reported at enrolment using a web-based anthropometric questionnaire ${ }^{35,36}$. BMI $125\left(\mathrm{~kg} / \mathrm{m}^{2}\right)$ was then computed by dividing weight by height squared. Data from specific questionnaires 126 and medication were used to retrieve the status regarding hypertension, dyslipidaemia, menopause, oral contraception and hormonal treatment for menopause.

\section{Sample selection}

129 For the present analysis, we included all participants who filled in at least three $24 \mathrm{~h}$ dietary records 130 during the first two years after inclusion $(n=115,536)$. Data used in the present paper were based on 131 participants included between 2009 and 2014 and followed up until May 2019 at the most. PNNS-GS2 132 was not computable for some participants due to missing data, mostly on organic food consumption. 133 For mortality analysis, participants were considered at risk when they were over 35 years old and 
134 accidental deaths were not considered as event. We also excluded all prevalent cases of the studied

135 outcome and subjects with missing covariates.

136 Detailed flowchart is presented in Figure 1. Exclusions led to a working sample of 80,964 participants 137 and analyses for risk of mortality, cancer and CVD were performed on 67,748, 75,634 and 80,269 138 participants respectively.

139 Statistical analysis

140 Analyses were hypothesis-oriented based on the relationship between PNNS-GS2 and prospective 141 occurrence of cancer, CVD or death. To investigate unexpected results, two non-prespecified analyses 142 were performed.

143 Quintiles (Q) of PNNS-GS2 were calculated for men and women separately.

144 Sociodemographic characteristics are presented across quintiles of PNNS-GS2.

145 We first estimated the association between PNNS-GS2 and incidence of non-accidental mortality 146 (among participants older than 35 years old), CVD and cancer, using a multivariable Cox proportional 147 hazard model with age as time-scale ${ }^{37}$. For each specific outcome, participants contributed follow-up 148 time from their entry in the study until the date of disease diagnosis, date of last completed 149 questionnaire, date of death or May 2019, whichever occurred first, so that each person contributed 150 only one endpoint to the analysis. The data were thus left-truncated and right-censored.

151 In a second set of analysis, we estimated the association between PNNS-GS2 and incidence of cancer 152 by localization (colorectal, prostate in men, and breast in women, i.e., the most frequent cancer 153 locations in the cohort). Here, the number of events, and therefore the power, was lower, which is why 154 the results were described in sex-specific tertiles instead of quintiles.

155 In order to account for competing events, we used cause-specific models, as it is recommended when 156 addressing inference questions ${ }^{38}$. Therefore, our models are censored on death not related to the event, 157 and on cancer on a different localization for cancer by localization.

158 Several models were used. The first model, m0, was only adjusted for sex. The model m1 was further 159 adjusted for energy intake without alcohol (continuous variable), number of completed 24h dietary 160 records (continuous variable), height (continuous variable), season of inclusion (4 modalities), 161 educational level (primary, secondary, university), monthly income ( $\leq 1800 € / \mathrm{cu}, 1800-2700 € / \mathrm{cu}$, $162>2700 € / \mathrm{cu},>2700 € / \mathrm{cu}$ ), occupation (farmers / self-employed, managerial staff, employees, students, 
163 manual workers, intermediates professions, retired, unemployed), cohabiting status (living alone,

164 cohabiting), baseline physical activity ([0-30[ min/day, [30-60[ $\mathrm{min} / \mathrm{day}, \geq 60 \mathrm{~min} / \mathrm{day})$, smoking 165 status (nonsmokers, former smokers, smokers), menopausal status in women (yes/no), hormonal 166 treatment for menopause in menopaused women (yes/no) and oral contraception in non-menopaused 167 women (yes/no). The model m2 was further adjusted for ethanol intake (continuous variable). Ethanol 168 intake is partially included in the PNNS-GS2 by design, but since it is a major risk factor, we wanted 169 to further consider it as a confounding variable. The model $\mathrm{m} 3$ was further adjusted for baseline BMI 170 (continuous variable).

171 For cancer analysis, models $\mathrm{m} 1$ and $\mathrm{m} 2$ were further adjusted for parental history of cancer (yes/no), 172 and for number of children (continuous variable) for breast cancer. For CVD analysis, models $\mathrm{m} 1$ and $173 \mathrm{~m} 2$ were further adjusted for parental history of CVD (yes/no) and an additional model m3 also 174 included baseline hypertension (yes/no), diabetes (yes/no) and dyslipidaemia status (yes/no).

175 Log-linearity was tested graphically for PNNS-GS2 using martingale residuals. All other continuous 176 covariates have been corrected for log-linearity using restricted cubic splines with 3 nodes ${ }^{39}$ using the $177 r m s$ package for $\mathrm{R}^{\circledR 40}$. Proportional hazard assumption was tested by performing a Grambsch-Therneau 178 test $^{41}$ and validated graphically using Schoenfeld residuals. All analyses were performed in men and 179 women altogether as no significant interaction with sex was ever detected.

180 As a sensitivity analysis, we replicated these analyses without considering early events ( $<2$ years after 181 inclusion) in order to reduce the reverse causality bias.

182 All statistical analyses were conducted using $\mathrm{R}^{\circledR}$ (version 3.4.2) and $\mathrm{SAS}^{\circledR}$ (version 7.15) with a 183 significance level of $5 \%$ for two-sided tests.

184 Patient involvement

185 The research hypothesis developed in this article corresponds to an important interest for the 186 participants involved in the NutriNet-Santé cohort and for the public in general. The results of this 187 study will be disseminated to the NutriNet-Santé participants through the cohort website, public 188 seminars, and a press release. 
191 The working sample was composed of $78 \%$ women and $22 \%$ men, providing on average $6.6(\mathrm{SD}=2.3)$

192 24h dietary records and $14.8(\mathrm{SD}=9.2)$ validated health questionnaires per person. Participants were 193 on average $44.4(\mathrm{SD}=14.6)$ years old. Mean PNNS-GS2 was $1.5(\mathrm{SD}=3.4)$ and median follow-up was $194 \quad 6.7$ years for cancer and 6.2 years for both mortality and MCV analyses.

195 Associations of PNNS-GS2 with baseline covariates are presented in Table 2. Higher adherence with 1962017 French FBDG was positively associated with age, education, income, cohabiting status and 197 physical activity, and negatively associated with baseline BMI, energy intake without alcohol, alcohol higher consumption of fruits, vegetables, legumes and whole grain cereals and higher frequency of organic food consumption, and negatively associated with higher consumption of red and processed meat, refined cereals and sweetened and alcoholic drinks.

203 The results of the prospective association between PNNS-GS2 and the risk of non-accidental mortality, all-sites cancer and CVD are presented in Table 3. After adjustment for confounding variables and regardless of the model, a higher adherence to the 2017 FBDG (measured by the PNNS-GS2) was negatively associated with the risk of death (828 cases), all cancer (2,577 cases) and CVD (964 cases). The results of the prospective association between PNNS-GS2 and the risk of cancer by type are presented in Table 4. After adjustment for confounding variables, the PNNS-GS2 was significantly associated with a lower risk of colorectal cancer, but no significant association could be found for prostate cancer or for breast cancer. These results prompted us to perform two sets of non-prespecified 211 analyses to investigate them.

212 First, as association with breast cancer was unexpectedly not significant ${ }^{42}$, we ran a non-prespecified 213 analysis, considering the risk of cancer either before or after the menopause. Results are presented in

214 Supplemental Table 2. Here, PNNS-GS2 was significantly associated with a lower risk of breast 215 cancer occurring after menopause, but with a higher risk of breast cancer before menopause. This latter 216 association persisted after further adjustment for eating disorder (yes/no) or after stratification on 217 number of children, BMI class ( $<25 \mathrm{vs} \geq 25$ ), physical activity, or parental history of cancer (data not 218 shown). 
219 Second, to make sure that the association between PNNS-GS2 and cancer was not entirely driven by

220 colorectal cancer, another non-prespecified analysis was run, considering all cancers except colorectal

221 to point out the association for other location. Results are presented in Supplemental Table 3. PNNS-

222 GS2 was still strongly associated with the risk of cancer, validating this result.

223 The results of the sensitivity analysis without considering early events are presented in Supplemental

224 Table 4. Although significance was reduced for lower quintiles, the PNNS-GS2 was still significantly

225 negatively associated with the risk of death, CVD and cancer in all models.

226 Schoenfeld residuals graphical analysis and Grambsch-Therneau tests showed that the multivariable

227 global assumption was never significantly violated. Log-linearity of PNNS-GS2's hazard rate was

228 validated graphically using Martingale residuals on the null model, which showed linear association

229 for death, all-sites cancer and CVD study. However, this hypothesis was slightly violated for cancers

230 by localization, hence results given for 1 point or 1 SD should be interpreted cautiously.

\section{Discussion}

232 In the present study, the adherence to the 2017 French FBDG assessed by the PNNS-GS2 was 233 associated, after adjustment for confounding variables, with a significantly lower risk of non234 accidental mortality (up to $-18 \%$ in Q5 vs Q1), cancer incidence or mortality (up to -17\% in Q5 vs 235 Q1), and cardiovascular diseases incidence or mortality (up to -27\% in Q5 vs Q1). The sensitivity 236 analysis which did not consider early events provided similar findings. PNNS-GS2 was also 237 significantly associated with a lower risk of colorectal cancer (up to $-17 \%$ for $1 \mathrm{SD}$ ), but was not 238 associated with prostate cancer or breast cancer.

239 Our results are consistent with the ones of a recent meta-analysis on association between dietary scores

240 and risk of death, CVD and cancer, Schwingshackl et al. ${ }^{5}$. Indeed, the authors reported a pooled risk 241 reduction of $-22 \%$ for all-cause mortality, $-22 \%$ for CVD incidence or mortality and $-16 \%$ for cancer 242 incidence or mortality when comparing high versus low adherence. Despites some differences, notably 243 in the food groups considered as harmful, cut-offs and scoring, all these dietary scores (namely the 244 Healthy Eating Index and the Alternate Healthy Eating Index, reflecting American guidelines, and the 245 Dietary Approaches to Stop Hypertension Score, designed to reduce hypertension) promote, similarly 246 to the PNNS-GS2, the consumption of fruits, vegetables, whole grains, nuts, and legumes, which are 247 known to lower the risk of CVD and some types of cancer ${ }^{43,44}$. 
248 The observed association with mortality, as the risk of cardiovascular diseases, was similar to number

249 of other studies on other diet quality scores, even if all do not reflect dietary guidelines ${ }^{4,5,45-48}$.

250 Concerning the risk of cancer, the strong negative association with diet quality as per the PNNS-GS2 251 was also consistent with the above-mentioned studies ${ }^{4,5,45,46}$. By location, the negative association 252 between PNNS-GS2 and risk of colorectal cancer was analogous to the one reported by Park et al., 253 which used dietary indices elaborated for the American population (HEI-2010 and AHEI-2010) in a 254 larger cohort ${ }^{49}$. Also, a colorectal cancer specific diet quality index, namely the CDQI, recently 255 developed and based on consumption of processed meat, fiber and dairy products, have documented 256 an inverse association with risk of colorectal cancer $^{50}$. Since these food groups are directly or indirectly 257 assessed by the PNNS-GS2, this is consistent with our results. Interestingly, a previous study 258 conducted in the NutriNet-Santé cohort study, with a shorter follow-up (6.4y), did not report any 259 association with AHEI and colorectal cancer ${ }^{51}$.

260 For breast cancer, a recent meta-analysis reported that it is negatively associated with a healthy/prudent 261 diet and positively associated with a Western $\operatorname{diet}^{52}$. This is consistent with current knowledge between 262 dietary components of the PNNS-GS2 and breast cancer, notably regarding vegetables, saturated fat, 263 and red and processed meat ${ }^{42}$, alcohol ${ }^{44}$, and dietary fibers ${ }^{53}$. The meta-analysis also presented a 264 subgroup analysis concluding that this latter association is significant in post-menopausal women but 265 remains marginal in pre-menopausal women ${ }^{52}$. This was also consistent with a large prospective study $266(\mathrm{~N}=96,959)^{54}$, considering diet quality as per American guidelines (AHEI-2010 score). As we found 267 no significant association between PNNS-GS2 and global risk of breast cancer, this motivated our non268 prespecified supplemental analysis, which also concluded to a significant protective association in 269 post-menopausal women. However, the association of PNNS-GS2 with a higher risk of breast cancer 270 in pre-menopausal women was rather puzzling. We could find only one study, published in 2013 on 27149,258 women, that reported a positive association between Mediterranean Diet and risk of cancer in 272 pre-menopausal women with a HR of $1.10(\mathrm{CI}=[1.01 ; 1.21])^{55}$, but this result was explained by the 273 promotion of moderate alcohol consumption, which is not promoted by the 2017 French FBDG. Since 274 other articles describe either a protective or a non-significant association, and since none of our 275 additional explorations could identify a relevant confounding factor, we attributed this finding to an 276 artifact or to residual, unidentified confounding as no mechanistic hypothesis was identified to explain 
this finding. Still, as these results come from non-prespecified analysis, they should be taken with

278 particular caution. Interestingly, the above-mentioned previous study conducted in the NutriNet-Santé 279 cohort study did not report any association with either AHEI, Medilite or mPNNS-GS and breast 280 cancer $^{51}$.

281 On the very few studies that have measured the association between diet quality and prostate cancer, 282 one has identified a significant association with HEI-2005 and AHEI-2010, but only in men screened 283 for PSA, which are obviously particularly at risk of prostate cancer ${ }^{56}$. This association was not 284 significant in men without PSA screening. Still, since our population was predominantly female, it would be interesting to replicate our study in a larger male population to benefit from a higher statistical power.

287 The main difference between the 2017 French FBDG and most FBDG is the consideration of organic 288 food. Indeed, organic food consumption have already been associated to an lower risk of cancer in the 289 NutriNet-Santé cohort ${ }^{57}$. Our results are consistent with this study regarding risk of all-sites, prostate 290 and post-menopausal breast cancer. However, no association was detected with colorectal and pre291 menopausal breast cancer risk in that study. We thus can hypothesize that for these specific cancers, 292 exposure to pesticides residues, which is one of the potential mechanisms for explaining the protective 293 effect of organic food consumption on cancer risk, may be of lesser importance than nutritional 294 properties of specific food groups like processed meat, fiber and dairy products. Another hypothesis may rely on statistical power since our population was larger and our follow-up time longer.

296 Some limitations of our study are worth noting. First, our analyses were based on volunteers who were 297 probably particularly concerned about their health, which limited the generalizability of our results. 298 Indeed, NutriNet-Santé participants are more likely to be women, well-educated, rather young, and to 299 have healthier behaviors than the general French population ${ }^{58}$. This selection bias could have led to a 300 lower NCD incidence and to a better diet quality than would have been estimated in the general 301 population, so we should expect that our results were underestimated, although overestimation bias 302 could not be totally ruled out. Second, residual confounding cannot be excluded in an observational 303 study, thus unmeasured behavioral factor as well as lack of precision in the measurement of covariates 304 and dietary records could have influenced the observed associations, although we accounted for a wide 305 range of potential confounders. Third, most of our data were self-declared and could therefore lack 
precision or suffer from social desirability bias. However, dietary data were validated against urinary and blood biomarkers ${ }^{29,30}$ and objective measurement ${ }^{36}$.

308 Nevertheless, although these limitations were noted, our study found strong negative associations between PNNS-GS2 and risk of non-accidental death, cancer and CVD. An important strength of this

310 work is its prospective design and its median follow-up duration of 6.7 years, which may have limited 311 reverse causality. Given the relatively large size of our population, this allowed a satisfying statistical 312 power. However, this power was restricted for studying risk of death, probably because of the selection 313 of a rather young and healthy population. Our dietary data were also highly accurate with on average $3146.624 \mathrm{~h}$ records per individual, thus accounting for daily variation. The PNNS-GS2 has been validated 315 in its construction and has proven a reliable construct in other studies ${ }^{17,18}$. Finally, our health events 316 (cancer and CVD) were validated by trained physicians, and data were linked to medico-administrative 317 databases, which should limit the declaration bias.

318 In conclusion, our findings suggest that following 2017 FBDG tend to be associated with a lower risk 319 of death, cancer and CVD. These results reinforce the validity and relevance of the updated 320 recommendations and should comfort the evidence supporting their dissemination.

\section{Acknowledgments}

322 The authors warmly thank all the volunteers of the NutriNet-Santé cohort. We also thank Cédric 323 Agaesse, Vristi Desan and Cynthia Perlin (dietitians); Thi Hong Van Duong, Younes Esseddik (IT 324 manager), Paul Flanzy, Régis Gatibelza, Jagatjit Mohinder and Aladi Timera (computer scientists); 325 Julien Allegre, Nathalie Arnault, Laurent Bourhis and Fabien Szabo de Edelenyi, PhD (supervisor) 326 (data-manager/statisticians); Fatoumata Diallo, MD, Roland Andrianasolo, MD, and Sandrine 327 Kamdem (physicians); and Nathalie Druesne-Pecollo, $\mathrm{PhD}$ (operational manager) for their technical 328 contribution to the NutriNet-Santé study.

\section{Financial Support}

330 The NutriNet-Santé study was supported by the following public institutions: Ministère de la Santé, 331 Santé Publique France, Institut National de la Santé et de la Recherche Médicale (INSERM), Institut 332 national de recherche pour l'agriculture, l'alimentation et l'environnement (INRAe), Conservatoire 333 National des Arts et Métiers (CNAM) and Université Sorbonne Paris Nord. Researchers were 
334 independent from funders. Funders had no role in the study design, the collection, analysis, and 335 interpretation of data, the writing of the report, and the decision to submit the article for publication. 336 Disclaimer: None of the authors declare any conflicts of interest.

\section{Author's contributions:}

338 EKG, SH, CJ and MT were responsible for the development of the design and protocol of the study; 339 EKG and DC were responsible for the design of the research. DC performed the statistical analysis 340 and wrote the paper; EKG supervised statistical analysis and paper writing; DC, CJ, RC, JB, MT, VD, 341 PLM, LF, SH, and EK-G were involved in interpreting the results and editing the manuscript for 342 important intellectual content. All authors read and approved the final manuscript. 


\section{References}

1. World Health Organization. Global Health Estimates 2016: Disease burden by Cause, Age, Sex, by Country and by Region, 2000-2016. Geneva, World Health Organization; 2018 [Internet]. 2018 [cited 2019 Jun 19]. Available from: https://www.who.int/news-room/fact-sheets/detail/the-top-10-causes-ofdeath

2. GBD 2017 Diet Collaborators. Health effects of dietary risks in 195 countries, 1990-2017: a systematic analysis for the Global Burden of Disease Study 2017. Lancet Lond Engl. 2019;393:1958-72.

3. Montagnese C, Santarpia L, Buonifacio M, Nardelli A, Caldara AR, Silvestri E, et al. European foodbased dietary guidelines: A comparison and update. Nutrition. 2015;31:908-15.

4. Lassale C, Gunter MJ, Romaguera D, Peelen LM, Van der Schouw YT, Beulens JWJ, et al. Diet Quality Scores and Prediction of All-Cause, Cardiovascular and Cancer Mortality in a Pan-European Cohort Study. PloS One. 2016;11:e0159025.

5. Schwingshackl L, Bogensberger B, Hoffmann G. Diet Quality as Assessed by the Healthy Eating Index, Alternate Healthy Eating Index, Dietary Approaches to Stop Hypertension Score, and Health Outcomes: An Updated Systematic Review and Meta-Analysis of Cohort Studies. J Acad Nutr Diet. 2018;118:74100.e11.

6. Dinu M, Pagliai G, Casini A, Sofi F. Mediterranean diet and multiple health outcomes: an umbrella review of meta-analyses of observational studies and randomised trials. Eur J Clin Nutr. 2018;72:30-43.

7. Galbete C, Kröger J, Jannasch F, Iqbal K, Schwingshackl L, Schwedhelm C, et al. Nordic diet, Mediterranean diet, and the risk of chronic diseases: the EPIC-Potsdam study. BMC Med. 2018;16:99.

8. Hansen SH, Overvad K, Hansen CP, Dahm CC. Adherence to national food-based dietary guidelines and incidence of stroke: A cohort study of Danish men and women. PloS One. 2018;13:e0206242.

9. Scheelbeek P, Green R, Papier K, Knuppel A, Alae-Carew C, Balkwill A, et al. Health impacts and environmental footprints of diets that meet the Eatwell Guide recommendations: analyses of multiple UK studies. BMJ Open. 2020;10:e037554.

10. Voortman T, Kiefte-de Jong JC, Ikram MA, Stricker BH, van Rooij FJA, Lahousse L, et al. Adherence to the 2015 Dutch dietary guidelines and risk of non-communicable diseases and mortality in the Rotterdam Study. Eur J Epidemiol. 2017;32:993-1005.

11. Springmann M, Spajic L, Clark MA, Poore J, Herforth A, Webb P, et al. The healthiness and sustainability of national and global food based dietary guidelines: modelling study. BMJ. 2020;370:m2322.

12. Ocké MC. Evaluation of methodologies for assessing the overall diet: dietary quality scores and dietary pattern analysis. Proc Nutr Soc. 2013;72:191-9.

13. Hu FB. Dietary pattern analysis: a new direction in nutritional epidemiology. Curr Opin Lipidol. 2002;13:3-9.

14. Jacobs DR, Gross MD, Tapsell LC. Food synergy: an operational concept for understanding nutrition. Am J Clin Nutr. 2009;89:1543S-1548S.

15. Burggraf C, Teuber R, Brosig S, Meier T. Review of a priori dietary quality indices in relation to their construction criteria. Nutr Rev. 2018;76:747-64. 
16. High Council for Public Health. French Nutrition and Health Programme's dietary guidelines for adults for the period 2017-2021 [Internet]. 2017 Feb. Available from: https://www.hcsp.fr/Explore.cgi/Telecharger?NomFichier=hcspa20170216_reperesalimentairesactua20 17_en.pdf

17. Chaltiel D, Adjibade M, Deschamps V, Touvier M, Hercberg S, Julia C, et al. Programme National Nutrition Santé - guidelines score 2 (PNNS-GS2): development and validation of a diet quality score reflecting the 2017 French dietary guidelines. Br J Nutr. 2019;1-12.

18. Chaltiel D, Julia C, Adjibade M, Touvier M, Hercberg S, Kesse-Guyot E. Adherence to the 2017 French dietary guidelines and adult weight gain: A cohort study. PLOS Med. 2019;16:e1003007.

19. Lauby-Secretan B, Scoccianti C, Loomis D, Grosse Y, Bianchini F, Straif K. Body Fatness and Cancer — Viewpoint of the IARC Working Group. N Engl J Med. 2016;375:794-8.

20. Hruby A, Manson JE, Qi L, Malik VS, Rimm EB, Sun Q, et al. Determinants and Consequences of Obesity. Am J Public Health. 2016;106:1656-62.

21. Bastien M, Poirier P, Lemieux I, Després J-P. Overview of Epidemiology and Contribution of Obesity to Cardiovascular Disease. Prog Cardiovasc Dis. 2014;56:369-81.

22. Hercberg S, Castetbon K, Czernichow S, Malon A, Mejean C, Kesse E, et al. The Nutrinet-Sante Study: a web-based prospective study on the relationship between nutrition and health and determinants of dietary patterns and nutritional status. BMC Public Health. 2010;10:242.

23. Le Moullec N, Deheeger M, Preziosi P, Monteiro P, Valeix P, Rolland-Cachera M-F, et al. Validation du manuel-photos utilisé pour l'enquête alimentaire de l'étude SU. VI. MAX. Cah Nutr Diététique. 1996;31:158-64.

24. Etude NutriNet-Santé. Table de Composition des Aliments de l'étude NutriNet-Santé [NutriNet-Santé Study Food Composition Database]. Economica: Paris,France; 2013.

25. Schofield WN. Predicting basal metabolic rate, new standards and review of previous work. Hum Nutr Clin Nutr. 1985;39 Suppl 1:5-41.

26. Black AE. Critical evaluation of energy intake using the Goldberg cut-off for energy intake:basal metabolic rate. A practical guide to its calculation, use and limitations. Int J Obes Relat Metab Disord J Int Assoc Study Obes. 2000;24:1119-30.

27. Goldberg GR, Black AE, Jebb SA, Cole TJ, Murgatroyd PR, Coward WA, et al. Critical evaluation of energy intake data using fundamental principles of energy physiology: 1. Derivation of cut-off limits to identify under-recording. Eur J Clin Nutr. 1991;45:569-81.

28. Touvier M, Kesse-Guyot E, Méjean C, Pollet C, Malon A, Castetbon K, et al. Comparison between an interactive web-based self-administered $24 \mathrm{~h}$ dietary record and an interview by a dietitian for large-scale epidemiological studies. Br J Nutr. 2011;105:1055-64.

29. Lassale C, Castetbon K, Laporte F, Camilleri GM, Deschamps V, Vernay M, et al. Validation of a Webbased, self-administered, non-consecutive-day dietary record tool against urinary biomarkers. Br J Nutr. 2015;113:953-62.

30. Lassale C, Castetbon K, Laporte F, Deschamps V, Vernay M, Camilleri GM, et al. Correlations between Fruit, Vegetables, Fish, Vitamins, and Fatty Acids Estimated by Web-Based Nonconsecutive Dietary Records and Respective Biomarkers of Nutritional Status. J Acad Nutr Diet. 2016;116:427-438.e5. 
31. Baudry J, Méjean C, Péneau S, Galan P, Hercberg S, Lairon D, et al. Health and dietary traits of organic food consumers: results from the NutriNet-Santé study. Br J Nutr. 2015;114:2064-73.

32. Santé Publique France. Avis d'experts relatif à l'évolution du discours public en matière de consommation d'alcool en France organisé par Santé publique France et l'Institut national du cancer. 2017 May.

33. Hallal PC, Victora CG. Reliability and validity of the International Physical Activity Questionnaire (IPAQ). Med Sci Sports Exerc. 2004;36:556.

34. INSEE. Definition - Consumption unit | Insee [Internet]. 2016 [cited 2018 Jul 27]. Available from: https://www.insee.fr/en/metadonnees/definition/c1802

35. Touvier M, Méjean C, Kesse-Guyot E, Pollet C, Malon A, Castetbon K, et al. Comparison between webbased and paper versions of a self-administered anthropometric questionnaire. Eur $\mathrm{J}$ Epidemiol. 2010;25:287-96.

36. Lassale C, Péneau S, Touvier M, Julia C, Galan P, Hercberg S, et al. Validity of web-based self-reported weight and height: results of the Nutrinet-Santé study. J Med Internet Res. 2013;15:e152.

37. Lamarca R, Alonso J, Gómez G, Muñoz A. Left-truncated data with age as time scale: an alternative for survival analysis in the elderly population. J Gerontol A Biol Sci Med Sci. 1998;53:M337-343.

38. Austin PC, Lee DS, Fine JP. Introduction to the Analysis of Survival Data in the Presence of Competing Risks. Circulation. 2016;133:601-9.

39. Harrell FEJ. Regression Modeling Strategies: With Applications to Linear Models, Logistic and Ordinal Regression, and Survival Analysis. Springer; 2015. 598 p.

40. Harrell FE. rms: Regression modeling strategies [Internet]. 2011. (f.harrell@ vanderbilt.edu). Available from: http://CRAN.R-project.org/package $=$ rms

41. Grambsch PM, Therneau TM. Proportional hazards tests and diagnostics based on weighted residuals. Biometrika. 1994;81:515-26.

42. Dandamudi A, Tommie J, Nommsen-Rivers L, Couch S. Dietary Patterns and Breast Cancer Risk: A Systematic Review. Anticancer Res. 2018;38:3209-22.

43. Mozaffarian D. Dietary and Policy Priorities for Cardiovascular Disease, Diabetes, and Obesity: A Comprehensive Review. Circulation. 2016;133:187-225.

44. AICR/WCRF. Diet, Nutrition, Physical activity, and the Prevention of Cancer: a global perspective. Washington, DC: American Institute for Cancer Research: American Institute for Cancer Research \& World Cancer Research Fund; 2018.

45. Onvani S, Haghighatdoost F, Surkan PJ, Larijani B, Azadbakht L. Adherence to the Healthy Eating Index and Alternative Healthy Eating Index dietary patterns and mortality from all causes, cardiovascular disease and cancer: a meta-analysis of observational studies. J Hum Nutr Diet. 2017;30:216-26.

46. Wang J, Haslam D, Ruan M, Chen F, Du M, Zhang FF. Diet Quality in Association with All-Cause, Cardiovascular, and Cancer Mortality Among US Adults: NHANES 1999-2010 (OR14-04-19). Curr Dev Nutr. 2019;3.

47. Trébuchet A, Julia C, Fézeu L, Touvier M, PharmaD DC, Hercberg S, et al. Prospective association between several dietary scores and risk of cardiovascular diseases: Is the Mediterranean diet equally 
associated to CVD compared to National Nutritional Scores? Am Heart J [Internet]. 2019 [cited 2019 Jul 29]; Available from: http://www.sciencedirect.com/science/article/pii/S000287031930184X

48. Aljuraiban GS, Gibson R, Oude Griep LM, Okuda N, Steffen LM, Van Horn L, et al. Perspective: The Application of A Priori Diet Quality Scores to Cardiovascular Disease Risk-A Critical Evaluation of Current Scoring Systems. Adv Nutr. 2020;11:10-24.

49. Park S-Y, Boushey CJ, Wilkens LR, Haiman CA, Le Marchand L. High-Quality Diets Associate With Reduced Risk of Colorectal Cancer: Analyses of Diet Quality Indexes in the Multiethnic Cohort. Gastroenterology. 2017;153:386-394.e2.

50. Vulcan A, Ericson U, Manjer J, Ohlsson B. A colorectal cancer diet quality index is inversely associated with colorectal cancer in the Malmö diet and cancer study. Eur J Cancer Prev Off J Eur Cancer Prev Organ ECP. 2018;

51. Lavalette C, Adjibade M, Srour B, Sellem L, Fiolet T, Hercberg S, et al. Cancer-Specific and General Nutritional Scores and Cancer Risk: Results from the Prospective NutriNet-Santé Cohort. Cancer Res. 2018;78:4427-35.

52. Xiao Y, Xia J, Li L, Ke Y, Cheng J, Xie Y, et al. Associations between dietary patterns and the risk of breast cancer: a systematic review and meta-analysis of observational studies. Breast Cancer Res BCR [Internet]. 2019 [cited $2020 \quad$ Jul 1];21. Available from: https://www.ncbi.nlm.nih.gov/pmc/articles/PMC6352362/

53. Latino-Martel P, Cottet V, Druesne-Pecollo N, Pierre FHF, Touillaud M, Touvier M, et al. Alcoholic beverages, obesity, physical activity and other nutritional factors, and cancer risk: A review of the evidence. Crit Rev Oncol Hematol. 2016;99:308-23.

54. Haridass V, Ziogas A, Neuhausen SL, Anton-Culver H, Odegaard AO. Diet Quality Scores Inversely Associated with Postmenopausal Breast Cancer Risk Are Not Associated with Premenopausal Breast Cancer Risk in the California Teachers Study. J Nutr. 2018;148:1830-7.

55. Couto E, Sandin S, Löf M, Ursin G, Adami H-O, Weiderpass E. Mediterranean Dietary Pattern and Risk of Breast Cancer. PLoS ONE [Internet]. 2013 [cited 2019 Jul 1];8. Available from: https://www.ncbi.nlm.nih.gov/pmc/articles/PMC3563544/

56. Bosire C, Stampfer MJ, Subar AF, Park Y, Kirkpatrick SI, Chiuve SE, et al. Index-based Dietary Patterns and the Risk of Prostate Cancer in the NIH-AARP Diet and Health Study. Am J Epidemiol. 2013;177:504-13.

57. Baudry J, Assmann K, Touvier M, Allès B, Seconda L, d'autres..., et al. Association of Frequency of Organic Food Consumption With Cancer Risk. JAMA Intern Med [Internet]. 2018 [cited 2018 Nov 5]; Available from: https://jamanetwork.com/journals/jamainternalmedicine/fullarticle/2707948

58. Andreeva VA, Salanave B, Castetbon K, Deschamps V, Vernay M, Kesse-Guyot E, et al. Comparison of the sociodemographic characteristics of the large NutriNet-Santé e-cohort with French Census data: the issue of volunteer bias revisited. J Epidemiol Community Health. 2015;69:893-8. 


\section{Figures}

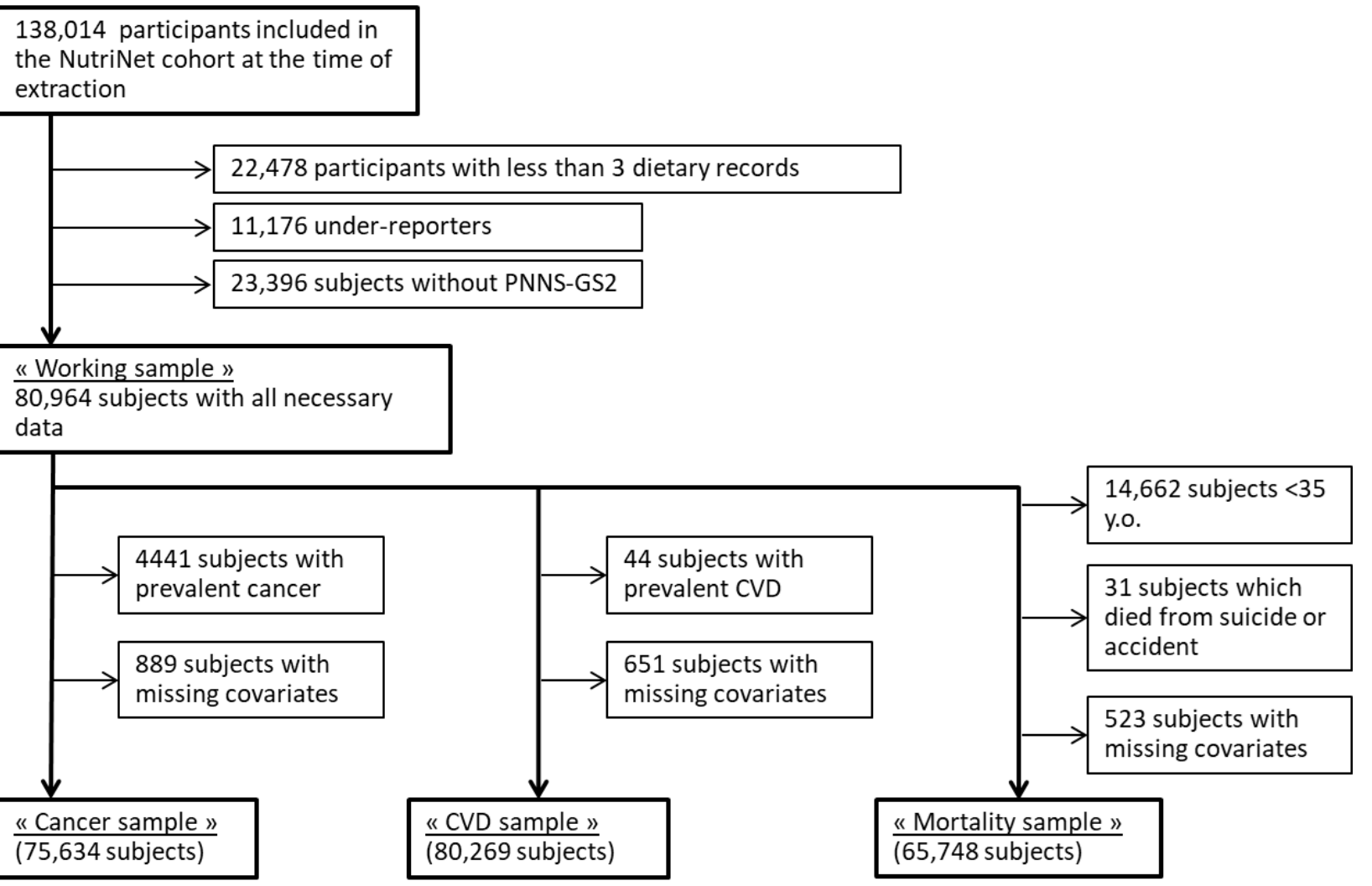

Figure 1 - Flowchart of subjects included in the present analysis of the NutriNet cohort. PNNS-GS2: Programme National Nutrition Santé - guidelines score 2, CVD: cardio-vascular diseases. 


\section{Tables}

Table 1 - PNNS-GS2 components and scoring

\begin{tabular}{|c|c|c|c|}
\hline Dietary components & Recommendation $^{\mathrm{a}}$ & $\begin{array}{l}\text { Servings per day unless otherwise is } \\
\text { stated }\end{array}$ & Score \\
\hline \multirow{10}{*}{$\begin{array}{l}\text { Fruits and vegetables } \\
\text { (weight=3) }\end{array}$} & \multirow{4}{*}{$\begin{array}{l}\text { At least } 5 \text { servings/day, with } 1 \text { max as juice and } \\
1 \text { max as dried }\end{array}$} & $\geq 0-<3.5$ & 0 \\
\hline & & $\geq 3.5-<5$ & 0.5 \\
\hline & & $\geq 5-<7.5$ & 1 \\
\hline & & $\geq 7.5$ & 2 \\
\hline & \multirow[t]{3}{*}{ Prefer organic fruits } & Most of the time & 0.5 \\
\hline & & Occasionally & 0.25 \\
\hline & & Never & 0 \\
\hline & \multirow[t]{3}{*}{ Prefer organic vegetables } & Most of the time & 0.5 \\
\hline & & Occasionally & 0.25 \\
\hline & & Never & 0 \\
\hline \multirow{4}{*}{$\begin{array}{l}\text { Nuts } \\
\text { (weight=1) }\end{array}$} & \multirow[t]{4}{*}{ A handful/day } & 0 & 0 \\
\hline & & ] $0-<0.5$ & 0.5 \\
\hline & & $\geq 0.5-<1.5$ & 1 \\
\hline & & $\geq 1.5$ & 0 \\
\hline \multirow{6}{*}{$\begin{array}{l}\text { Legumes } \\
\text { (weight=1) }\end{array}$} & \multirow[t]{3}{*}{ At least 2 servings/week } & 0 /week & 0 \\
\hline & & $>0-<2$ /week & 0.5 \\
\hline & & $\geq 2$ /week & 1 \\
\hline & \multirow[t]{3}{*}{ Prefer organic legumes } & Most of time & 0.5 \\
\hline & & Occasionally & 0.25 \\
\hline & & Never & 0 \\
\hline \multirow{10}{*}{$\begin{array}{l}\text { Whole-grain food } \\
\text { (weight=2) }\end{array}$} & \multirow[t]{4}{*}{ Every day } & 0 & 0 \\
\hline & & $>0-<1$ & 0.5 \\
\hline & & $\geq 1-<2$ & 1 \\
\hline & & $\geq 2$ & 1.5 \\
\hline & \multirow[t]{3}{*}{ Prefer organic bread } & Most of the time & 0.5 \\
\hline & & Occasionally & 0.25 \\
\hline & & Never & 0 \\
\hline & \multirow[t]{3}{*}{ Prefer organic grains } & Most of the time & 0.5 \\
\hline & & Occasionally & 0.25 \\
\hline & & Never & 0 \\
\hline \multirow{4}{*}{$\begin{array}{l}\text { Milk and dairy products } \\
(\text { weight }=1)\end{array}$} & \multirow[t]{4}{*}{2 servings/day } & $\geq 0-<0.5$ & 0 \\
\hline & & $\geq 0.5-<1.5$ & 0.5 \\
\hline & & $\geq 1.5-<2.5$ & 1 \\
\hline & & $\geq 2.5$ & 0 \\
\hline \multirow{3}{*}{$\begin{array}{l}\text { Red meat } \\
(\text { weight }=2)\end{array}$} & \multirow[t]{3}{*}{ Limit consumption } & $\geq 0-<500 \mathrm{~g} /$ week & 0 \\
\hline & & $\geq 500-<750 \mathrm{~g} /$ week & -1 \\
\hline & & $\geq 750 \mathrm{~g} /$ week & -2 \\
\hline \multirow{5}{*}{$\begin{array}{l}\text { Processed meat } \\
\text { (weight }=3 \text { ) }\end{array}$} & Limit consumption & $\geq 0-<150 \mathrm{~g} /$ week & 0 \\
\hline & & $\geq 150-<300 \mathrm{~g} /$ week & -1 \\
\hline & & $\geq 300 \mathrm{~g} /$ week & -2 \\
\hline & Prefer white ham over other processed meat ${ }^{c}$ & Ratio $<50 \%$ & 0 \\
\hline & & Ratio $\geq 50 \%$ & 0.5 \\
\hline Fish and seafood & 2 servings/week & $\geq 0-<1.5$ servings /week & 0 \\
\hline (weight=2) & & $\geq 1.5-<2.5$ servings /week & 1 \\
\hline & & $\geq 2.5-<3.5$ servings /week & 0.5 \\
\hline & & $\geq 3.5$ servings /week & 0 \\
\hline & Fatty fish 1 serving/week & $\geq 0-<0.5$ servings/week & 0 \\
\hline & & $\geq 0.5-<1.5$ servings/week & 1 \\
\hline & & $\geq 1.5$ servings/week & 0 \\
\hline Added fat & Limit consumption & $>16 \%$ of EIWA ${ }^{f}$ & 0 \\
\hline (weight=2) & & $\leq 16 \%$ of EIWA & 1.5 \\
\hline & Prefer vegetal fat over animal fat & Ratio $>50 \%$ & 1 \\
\hline & & Ratio $\leq 50 \%$ & 0 \\
\hline & Prefer ALA-rich ${ }^{\mathrm{f}}$ and olive oils over other oils & Ratio $<50 \%$ & 0 \\
\hline & & Ratio $\geq 50 \%$ & 1 \\
\hline Sugary foods & Limit consumption & $<10 \%$ of EIWA & 0 \\
\hline$($ weight=3) & & $\geq 10-15[\%$ of EIWA & -1 \\
\hline & & $\geq 15 \%$ of EIWA & -2 \\
\hline
\end{tabular}




\begin{tabular}{|c|c|c|c|}
\hline Dietary components & Recommendation $^{\mathrm{a}}$ & $\begin{array}{l}\text { Servings per day unless otherwise is } \\
\text { stated }\end{array}$ & Score \\
\hline $\begin{array}{l}\text { Sweet-tasting beverages } \\
\mathrm{d} \\
(\text { weight }=3)\end{array}$ & Limit consumption & $\begin{array}{l}0 \mathrm{~mL} / \text { day } \\
>0-250<\mathrm{mL} / \text { day } \\
\geq 250-750<\mathrm{mL} / \text { day } \\
\geq 750 \mathrm{~mL} \mathrm{~mL} / \text { day }\end{array}$ & $\begin{array}{l}0 \\
-0.5 \\
-1 \\
-2\end{array}$ \\
\hline $\begin{array}{l}\text { Alcoholic beverages } \\
(\text { weight=3) }\end{array}$ & Limit consumption & $\begin{array}{l}0 \mathrm{~g} / \mathrm{week} \\
>0-\leq 100 \mathrm{~g} / \mathrm{week} \\
>100-\leq 150 \mathrm{~g} / \text { week } \\
>150-\leq 200 \mathrm{~g} / \text { week } \\
>200 \mathrm{~g} / \text { week }\end{array}$ & $\begin{array}{l}0.5 \\
0 \\
-1 \\
-1.5 \\
-2\end{array}$ \\
\hline $\begin{array}{l}\text { Salt } \\
(\text { weight=3) }\end{array}$ & Limit consumption & $\begin{array}{l}<6 \text { g/day } \\
\geq 6-<8 \text { g/day } \\
\geq 8-<10 \text { g/day } \\
\geq 10-<12 \text { g/day } \\
\geq 12 \text { g/day }\end{array}$ & $\begin{array}{l}1 \\
0 \\
-0.5 \\
-1 \\
-2\end{array}$ \\
\hline
\end{tabular}

$\overline{\text { Abbreviations: EIWA }}=$ energy intake without alcohol, ALA $=\alpha$-linolenic acid

${ }^{\text {a }}$ Principal benchmark are written in bold.

${ }^{\mathrm{b}}$ Servings per day unless otherwise is stated

${ }^{\mathrm{c}}$ Conditional: the 0.5 bonus point only occurs if total processed meat consumption is more than $150 \mathrm{~g} / \mathrm{week}$

${ }^{\mathrm{d}}$ Sweetened beverages are specifically sweet beverages, artificially sweetened beverages and fruit juices 
Table 2 - Baseline characteristics of the participants by quintile of PNNS-GS2, NutriNet-Santé study, $\mathrm{N}=\mathbf{8 0 , 9 6 4}$.

\begin{tabular}{|c|c|c|c|c|c|c|}
\hline & Total & Q1 & Q2 & Q3 & $\mathrm{Q} 4$ & Q5 \\
\hline PNNS-GS2 mean (sd) & $1.5(3.4)$ & $-3.0(1.9)$ & $-0.2(1.3)$ & $1.6(1.1)$ & $3.3(1)$ & $6.0(1.5)$ \\
\hline PNNS-GS2 range in women & & $<-0.6$ & $-0.6-1.3$ & $1.3-2.9$ & $2.9-4.7$ & $>12.4$ \\
\hline PNNS-GS2 range in men & & $<-3.4$ & $-3.4--1.3$ & $-1.3-0.7$ & $0.7-2.8$ & $>12.6$ \\
\hline Age at inclusion (years) & $44.4(14.6)$ & $40.4(14)$ & $42.8(14.4)$ & $44.5(14.5)$ & $46.1(14.5)$ & $48.1(14.2)$ \\
\hline BMI $\left(\mathrm{kg} / \mathrm{m}^{2}\right)$ & $23.8(4.5)$ & $24.6(5.2)$ & $24.1(4.7)$ & $23.8(4.4)$ & $23.6(4.2)$ & $22.9(3.9)$ \\
\hline Height $(\mathrm{cm})$ & $166.5(8.7)$ & $167.6(8.8)$ & $166.9(8.8)$ & $166.4(8.7)$ & $166.1(8.4)$ & $165.7(8.8)$ \\
\hline $\begin{array}{l}\text { Energy intake without alcohol } \\
(\mathrm{kcal} / \mathrm{d})\end{array}$ & $1816(449)$ & 2047 (472) & $1890(448)$ & $1790(410)$ & $1713(407)$ & $1642(388)$ \\
\hline Ethanol intake $(\mathrm{g} / \mathrm{d})$ & $7.9(11.5)$ & $14.1(16.6)$ & $9.1(12.0)$ & $7.2(9.7)$ & $5.5(7.4)$ & $3.8(5.7)$ \\
\hline \multicolumn{7}{|l|}{ Sex } \\
\hline Male & $21.9 \%$ & $21.9 \%$ & $21.8 \%$ & $22.0 \%$ & $21.8 \%$ & $22.0 \%$ \\
\hline Female & $78.1 \%$ & $78.1 \%$ & $78.2 \%$ & $78.0 \%$ & $78.2 \%$ & $78.0 \%$ \\
\hline \multicolumn{7}{|l|}{ Menopausal status ${ }^{b}$} \\
\hline Postmenopausal & $29.0 \%$ & $18.9 \%$ & $24.3 \%$ & $28.6 \%$ & $33.9 \%$ & $39.4 \%$ \\
\hline Premenopausal & $71.0 \%$ & $81.1 \%$ & $75.7 \%$ & $71.4 \%$ & $66.1 \%$ & $60.6 \%$ \\
\hline \multicolumn{7}{|l|}{ Hormone Replacement } \\
\hline \multicolumn{7}{|l|}{ Therapy for menopause ${ }^{b}$} \\
\hline On HRT & $23.9 \%$ & $24.3 \%$ & $23.7 \%$ & $24.2 \%$ & $24.3 \%$ & $23.1 \%$ \\
\hline Not on HRT & $76.1 \%$ & $75.7 \%$ & $76.3 \%$ & $75.8 \%$ & $75.7 \%$ & $76.9 \%$ \\
\hline \multicolumn{7}{|l|}{ Pill contraception ${ }^{\mathrm{b}}$} \\
\hline On pill & $37.0 \%$ & $42.9 \%$ & $39.9 \%$ & $36.9 \%$ & $33.6 \%$ & $29.0 \%$ \\
\hline Not on pill & $55.3 \%$ & $50.9 \%$ & $53.2 \%$ & $55.4 \%$ & $57.5 \%$ & $61.4 \%$ \\
\hline \multicolumn{7}{|l|}{ Education } \\
\hline Primary & $1.0 \%$ & $1.3 \%$ & $1.1 \%$ & $0.9 \%$ & $1.0 \%$ & $0.9 \%$ \\
\hline Secondary & $34.1 \%$ & $36.8 \%$ & $34.4 \%$ & $33.8 \%$ & $33.1 \%$ & $32.5 \%$ \\
\hline University & $64.8 \%$ & $61.9 \%$ & $64.5 \%$ & $65.3 \%$ & $65.9 \%$ & $66.6 \%$ \\
\hline \multicolumn{7}{|l|}{ Occupational category } \\
\hline Farmers / self-employed & $1.9 \%$ & $2.2 \%$ & $2.0 \%$ & $1.7 \%$ & $1.8 \%$ & $1.9 \%$ \\
\hline Managerial staff & $23.6 \%$ & $21.7 \%$ & $23.0 \%$ & $23.6 \%$ & $24.8 \%$ & $24.7 \%$ \\
\hline Employees & $17.5 \%$ & $21.4 \%$ & $18.9 \%$ & $17.9 \%$ & $15.6 \%$ & $13.9 \%$ \\
\hline Students & $7.3 \%$ & $9.1 \%$ & $8.1 \%$ & $7.4 \%$ & $6.4 \%$ & $5.6 \%$ \\
\hline Manual workers & $1.1 \%$ & $1.8 \%$ & $1.3 \%$ & $1.0 \%$ & $0.8 \%$ & $0.7 \%$ \\
\hline Intermediates professions & $17.4 \%$ & $17.6 \%$ & $17.8 \%$ & $17.7 \%$ & $17.3 \%$ & $16.5 \%$ \\
\hline Retired & $19.5 \%$ & $13.3 \%$ & $17.4 \%$ & $19.6 \%$ & $22.1 \%$ & $25.1 \%$ \\
\hline Unemployed & $11.7 \%$ & $12.9 \%$ & $11.4 \%$ & $11.1 \%$ & $11.2 \%$ & $11.7 \%$ \\
\hline \multicolumn{7}{|l|}{ Income $^{\mathrm{c}}$} \\
\hline$\leq 1800 € / \mathrm{cu}^{\mathrm{f}}$ & $45.3 \%$ & $52.1 \%$ & $47.6 \%$ & $44.7 \%$ & $42.2 \%$ & $39.9 \%$ \\
\hline $1800-2700 € / \mathrm{cu}$ & $26.9 \%$ & $25.0 \%$ & $26.5 \%$ & $26.9 \%$ & $27.8 \%$ & $28.1 \%$ \\
\hline$>2700 € / \mathrm{cu}$ & $27.8 \%$ & $22.9 \%$ & $26.0 \%$ & $28.4 \%$ & $29.9 \%$ & $32.0 \%$ \\
\hline$>2700 € / \mathrm{cu}$ & $27.8 \%$ & $22.9 \%$ & $26.0 \%$ & $28.4 \%$ & $29.9 \%$ & $32.0 \%$ \\
\hline \multicolumn{7}{|l|}{ Physical activity } \\
\hline$[0-30[\mathrm{~min} /$ day & $26.7 \%$ & $32.0 \%$ & $29.1 \%$ & $27.3 \%$ & $24.7 \%$ & $20.3 \%$ \\
\hline$[30-60[\mathrm{~min} /$ day & $24.4 \%$ & $23.4 \%$ & $25.3 \%$ & $24.5 \%$ & $24.8 \%$ & $24.1 \%$ \\
\hline$\geq 60 \mathrm{~min} /$ day & $48.9 \%$ & $44.5 \%$ & $45.5 \%$ & $48.3 \%$ & $50.5 \%$ & $55.7 \%$ \\
\hline \multicolumn{7}{|l|}{ Smoking } \\
\hline Non smokers & $50.2 \%$ & $43.8 \%$ & $49.6 \%$ & $51.0 \%$ & $52.1 \%$ & $54.4 \%$ \\
\hline Former smokers & $34.3 \%$ & $32.6 \%$ & $33.2 \%$ & $34.5 \%$ & $35.3 \%$ & $36.1 \%$ \\
\hline Smokers & $15.5 \%$ & $23.6 \%$ & $17.2 \%$ & $14.6 \%$ & $12.6 \%$ & $9.5 \%$ \\
\hline \multicolumn{7}{|l|}{ Living status } \\
\hline Living alone & $27.7 \%$ & $26.5 \%$ & $26.3 \%$ & $26.9 \%$ & $28.4 \%$ & $30.3 \%$ \\
\hline Cohabiting & $72.3 \%$ & $73.5 \%$ & $73.7 \%$ & $73.0 \%$ & $71.5 \%$ & $69.7 \%$ \\
\hline
\end{tabular}

${ }^{a}$ Values are percentages or mean (standard deviation) as appropriate. All p-values were $\leq 0.0001$

${ }^{\mathrm{b}}$ Percentages are given in women only for menopausal status, in postmenopausal women for HRT and in premenopausal women only for pill contraception

${ }^{\mathrm{c}} \mathrm{cu}=$ consumption unit 
Table 3 - Prospective association between PNNS-GS2 and risk of non-accidental mortality (for participants aged 35+), all-sites cancer and cardiovascular diseases, NutriNet-Santé study a

\begin{tabular}{|c|c|c|c|c|c|c|c|}
\hline & Q1 & Q2 & Q3 & Q4 & Q5 & $1 \mathrm{pt}$ & $\mathrm{pval}^{\mathrm{b}}$ \\
\hline \multicolumn{8}{|l|}{ Mortality } \\
\hline $\mathrm{n}$ & 13,177 & 13,152 & 13,194 & 13,127 & 13,098 & 65,748 & \\
\hline Events & 160 & 184 & 150 & 169 & 165 & 828 & \\
\hline $\begin{array}{l}\text { Person- } \\
\text { years }\end{array}$ & 84,399 & 85,650 & 85,424 & 85,199 & 84,704 & 425,377 & \\
\hline $\mathrm{HR}_{\mathrm{m} 0}{ }^{\mathrm{c}}$ & 1 & $0.99[0.80-1.23]$ & $0.76[0.61-0.95]$ & $0.80[0.64-0.99]$ & $0.73[0.59-0.91]$ & $0.96[0.94-0.98]$ & 0.0002 \\
\hline $\mathrm{HR}_{\mathrm{m} 1}{ }^{\mathrm{d}}$ & 1 & $1.06[0.85-1.31]$ & $0.84[0.67-1.06]$ & $0.88[0.70-1.10]$ & $0.84[0.66-1.06]$ & $0.97[0.95-1.00]$ & 0.03 \\
\hline $\mathrm{HR}_{\mathrm{m} 2}{ }^{\mathrm{e}}$ & 1 & 1.04 [0.83-1.29] & 0.81 [0.64-1.03] & 0.84 [0.66-1.06] & $0.77[0.60-1.00]$ & $0.96[0.94-0.99]$ & 0.005 \\
\hline $\mathrm{HR}_{\mathrm{m} 3}{ }^{\mathrm{f}}$ & 1 & $1.06[0.85-1.32]$ & 0.84 [0.66-1.07] & $0.87[0.69-1.12]$ & $0.82[0.63-1.06]$ & $0.97[0.95-1.00]$ & 0.02 \\
\hline \multicolumn{8}{|l|}{ Cancer } \\
\hline $\mathrm{n}$ & 15,174 & 15,115 & 15,151 & 15,121 & 15,073 & 75,634 & \\
\hline Events & 452 & 503 & 559 & 548 & 515 & 2,577 & \\
\hline $\begin{array}{l}\text { Person- } \\
\text { years }\end{array}$ & 89,091 & 90,950 & 92,029 & 92,283 & 92,526 & 456,878 & \\
\hline $\mathrm{HR}_{\mathrm{m} 0}{ }^{\mathrm{c}}$ & 1 & $0.95[0.84-1.08]$ & $0.97[0.86-1.10]$ & $0.88[0.77-0.99]$ & $0.75[0.66-0.85]$ & $0.97[0.96-0.98]$ & $<0.0001$ \\
\hline $\mathrm{HR}_{\mathrm{ml}}{ }^{\mathrm{d}}$ & 1 & $0.95[0.84-1.08]$ & $0.97[0.85-1.10]$ & $0.88[0.77-1.00]$ & $0.76[0.66-0.87]$ & $0.97[0.95-0.98]$ & $<0.0001$ \\
\hline $\mathrm{HR}_{\mathrm{m} 2}{ }^{\mathrm{e}}$ & 1 & $0.98[0.86-1.11]$ & $1.00[0.88-1.14]$ & $0.92[0.80-1.06]$ & $0.80[0.69-0.92]$ & $0.97[0.96-0.99]$ & $<0.0001$ \\
\hline $\mathrm{HR}_{\mathrm{m} 3}{ }^{\mathrm{f}}$ & 1 & $0.99[0.87-1.13]$ & $1.02[0.89-1.17]$ & $0.94[0.82-1.08]$ & $0.83[0.71-0.96]$ & $0.97[0.96-0.99]$ & 0.0009 \\
\hline \multicolumn{8}{|l|}{ CVD } \\
\hline $\mathrm{n}$ & 16,105 & 16,129 & 15,972 & 16,146 & 15,917 & 80,269 & \\
\hline Events & 187 & 181 & 183 & 199 & 214 & 964 & \\
\hline $\begin{array}{l}\text { Person- } \\
\text { years }\end{array}$ & 95,637 & 98,443 & 98,638 & 99,882 & 98,869 & 491,469 & \\
\hline $\mathrm{HR}_{\mathrm{m} 0}{ }^{\mathrm{c}}$ & 1 & $0.81[0.66-0.99]$ & $0.75[0.61-0.91]$ & $0.75[0.61-0.91]$ & $0.74[0.60-0.90]$ & $0.97[0.95-0.99]$ & 0.003 \\
\hline $\mathrm{HR}_{\mathrm{ml}}{ }^{\mathrm{d}}$ & 1 & $0.81[0.66-1.00]$ & $0.74[0.60-0.91]$ & $0.74[0.60-0.91]$ & $0.73[0.59-0.91]$ & $0.97[0.95-0.99]$ & 0.007 \\
\hline $\mathrm{HR}_{\mathrm{m} 2}{ }^{\mathrm{e}}$ & 1 & $0.78[0.63-0.96]$ & $0.69[0.55-0.86]$ & $0.67[0.53-0.84]$ & $0.64[0.51-0.81]$ & $0.96[0.94-0.98]$ & 0.0004 \\
\hline $\mathrm{HR}_{\mathrm{m} 3}{ }^{\mathrm{f}}$ & 1 & $0.80[0.64-0.98]$ & $0.72[0.58-0.90]$ & $0.71[0.57-0.90]$ & $0.71[0.56-0.91]$ & $0.97[0.95-0.99]$ & 0.01 \\
\hline $\mathrm{HR}_{\mathrm{m} 4} \mathrm{~g}$ & 1 & $0.80[0.65-0.99]$ & $0.73[0.59-0.91]$ & $0.73[0.58-0.92]$ & $0.73[0.58-0.93]$ & $0.97[0.95-1.00]$ & 0.03 \\
\hline
\end{tabular}

${ }^{a}$ For each model, 3 Cox regressions were fitted: one with PNNS-GS2 in quintiles, one with PNNS-GS2 for 1 point and one with PNNS-GS2 for 1 SD. Bold values are significant for alpha at 5\%.

${ }^{\mathrm{b}} \mathrm{p}$-values are drawn from a Wald test for the PNNS-SG2 in continuous, which effect is presented for 1 point

${ }^{\mathrm{c}} \mathrm{m} 0$ is the base model, adjusted only for sex (and age as time-scale).

${ }^{\mathrm{d}} \mathrm{m} 1$ is $\mathrm{m} 0$, further adjusted for energy intake without alcohol, number of completed 24h dietary records, height, season of inclusion, physical activity, occupation, smoking status, educational level, monthly income, cohabiting status, menopausal status in women, hormonal treatment for menopause in menopaused women and oral contraception in non-menopaused women, parental history (for cancer and CVD only) and number of children (for cancer and in women only).

${ }^{\mathrm{e}} \mathrm{m} 2$ is $\mathrm{m} 1$, further adjusted for ethanol intake.

${ }^{\mathrm{f}} \mathrm{m} 3$ is $\mathrm{m} 2$, further adjusted for baseline BMI.

${ }^{\mathrm{g}} \mathrm{m} 4$, a complementary model for CVD, is $\mathrm{m} 3$, further adjusted for baseline hypertension status and dyslipidaemia status. 
Table 4 - Prospective association between PNNS-GS2 and risk of cancer by localization, NutriNet-Santé study ${ }^{a}$

\begin{tabular}{lllllll}
\hline & $\mathrm{T} 1$ & $\mathrm{~T} 2$ & $\mathrm{~T} 3$ & $1 \mathrm{pt}$ & $1 \mathrm{SD}$ & $\mathrm{p}^{\mathrm{b}}$ \\
\hline Colorectal & & & & & & \\
$\mathrm{n}$ & 25231 & 25219 & 25184 & 75634 & 75634 & \\
Events & 56 & 88 & 63 & 207 & 207 & \\
Person-years & 148689 & 152448 & 153143 & 454281 & 454281 & \\
$\mathrm{HR}_{\mathrm{m} 2}{ }^{\mathrm{c}}$ & 1 & $1.18[0.82-1.69]$ & $0.66[0.43-1.01]$ & $\mathbf{0 . 9 4}[\mathbf{0 . 8 9 - 0 . 9 9}]$ & $\mathbf{0 . 8 2}[\mathbf{0 . 6 9 - 0 . 9 8}]$ & $\mathbf{0 . 0 3}$ \\
\hline Prostate/ & & & & & & \\
$\mathrm{n}$ & 5524 & 5509 & 5509 & 16542 & 16542 & \\
Events & 98 & 116 & 94 & 308 & 308 & \\
Person-years & 33161 & 33442 & 33674 & 100277 & 100277 & \\
$\mathrm{HR}_{\mathrm{m} 2}{ }^{\mathrm{c}}$ & 1 & $1.13[0.85-1.52]$ & $0.90[0.63-1.27]$ & $0.98[0.94-1.02]$ & $0.92[0.79-1.07]$ & 0.28 \\
\hline Breast & & & & & & \\
$\mathrm{n}$ & 19707 & 19710 & 19675 & 59092 & 59092 & \\
events & 239 & 244 & 276 & 759 & 759 & \\
Person-years & 115528 & 119006 & 119469 & 354004 & 354004 & \\
$\mathrm{HR}_{\mathrm{m} 2}{ }^{\mathrm{c}}$ & 1 & $0.85[0.70-1.03]$ & $0.85[0.69-1.04]$ & $0.98[0.95-1.01]$ & $0.94[0.86-1.02]$ & 0.15 \\
\hline
\end{tabular}

${ }^{a}$ Bold value are significant for alpha at $5 \%$.

${ }^{\mathrm{b}} \mathrm{p}$-values are drawn from a Wald test for the PNNS-SG2 in continuous, which effect is presented for 1 point and for 1 standard deviation. As log-linearity hypothesis of Cox model was not fully satisfying on these outcomes, results should be treated with caution.

${ }^{\mathrm{c}}$ model $\mathrm{m} 2$ is adjusted on sex, energy intake without alcohol, ethanol intake, number of completed $24 \mathrm{~h}$ dietary records, height, season of inclusion, physical activity, occupation, smoking status, educational level, monthly income, cohabiting status, baseline BMI, menopausal status in women, hormonal treatment for menopause in menopaused women and oral contraception in nonmenopaused women, parental history of cancer and number of children (in women only). 


\section{Supplemental Tables}

Supplemental Table 1 - Food group consumption by quintile of the PNNS-GS2, NutriNet-Santé study, 2009, $\mathrm{N}=80,965^{\text {a }}$

\begin{tabular}{|c|c|c|c|c|c|c|c|}
\hline $\begin{array}{l}\text { Energy intake } \\
\text { without alcohol (kcal) }\end{array}$ & $1816.7(449.2)$ & $2047.5(472.5)$ & $1889.6(447.8)$ & $1789.7(410.1)$ & $1712.8(406.8)$ & $1642.5(388.2)$ & $\begin{array}{l}-0.419 \\
{[-0.425 ;} \\
0.414]\end{array}$ \\
\hline Proteins & $17.5(3.6)$ & $17.5(3.7)$ & $17.5(3.6)$ & $17.6(3.6)$ & $17.6(3.6)$ & $17.2(3.8)$ & $\begin{array}{l}-0.032 \\
{[-0.039 ;-0.025]}\end{array}$ \\
\hline Carbohydrates & $42.8(6.3)$ & $40.8(6.2)$ & $42.1(5.9)$ & $42.8(6.0)$ & $43.6(6.1)$ & $44.7(6.6)$ & $\begin{array}{l}0.198 \\
{[0.192 ; 0.205]}\end{array}$ \\
\hline Lipids & $39.4(5.9)$ & $41.4(5.4)$ & $40.1(5.5)$ & $39.2(5.6)$ & $38.4(5.9)$ & $37.8(6.4)$ & $\begin{array}{l}-0.198 \\
{[-0.205 ;-0.192]}\end{array}$ \\
\hline Fruits (g) & $201.3(144.7)$ & $121.1(108.4)$ & $166.1(119.4)$ & $195.1(124.3)$ & $228.8(136.3)$ & $296.1(165.5)$ & $\begin{array}{l}0.41 \\
{[0.404 ; 0.416]}\end{array}$ \\
\hline Vegetables (g) & $221.4(111.2)$ & $172.7(95.7)$ & $200.2(99.5)$ & $217.9(99.8)$ & $238.3(108.5)$ & $278.2(121.3)$ & $\begin{array}{l}0.321 \\
{[0.315 ; 0.327]}\end{array}$ \\
\hline Fruit juices (mL) & $53.5(73.1)$ & $55.2(82.9)$ & $55.9(75.3)$ & $54.8(70.2)$ & $53.4(69.2)$ & $48.3(66.8)$ & $\begin{array}{l}-0.031 \\
{[-0.038 ;-0.024]}\end{array}$ \\
\hline Vegetables juices (mL) & $1.8(14.3)$ & $1.2(12.7)$ & $1.3(13.3)$ & $1.4(11.1)$ & $1.9(14.5)$ & $3.1(18.8)$ & $\begin{array}{l}0.045 \\
{[0.038 ; 0.052]}\end{array}$ \\
\hline Legumes (g) & $11.8(21.6)$ & $7.4(17.4)$ & $9.0(17.6)$ & $10.4(18.5)$ & $12.5(20.7)$ & $19.9(29.3)$ & $\begin{array}{l}0.198 \\
{[0.191 ; 0.204]}\end{array}$ \\
\hline Potatoes and tubers (g) & $45.7(39.8)$ & $47.5(43.9)$ & $45.4(39.7)$ & $45.4(38.8)$ & $45.3(37.8)$ & $45.0(38.5)$ & $\begin{array}{l}-0.02 \\
{[-0.027 ;-0.013]}\end{array}$ \\
\hline Whole-grain cereals (g) & $34.9(43.8)$ & $16.8(30.3)$ & $26(36.1)$ & $31.9(38.5)$ & $40.6(44.7)$ & $59.3(53.3)$ & $\begin{array}{l}0.331 \\
{[0.325 ; 0.337]}\end{array}$ \\
\hline Refined cereals (g) & $141.0(68.9)$ & $145.4(71.6)$ & $147.2(70.1)$ & $145.2(67.5)$ & $141.3(66.8)$ & $125.6(65.8)$ & $\begin{array}{l}-0.096 \\
{[-0.102 ;-0.089]}\end{array}$ \\
\hline Breakfast cereals (g) & $6.7(14.6)$ & $4.5(12.8)$ & $5.8(13.7)$ & $6.5(13.9)$ & $7.5(15.5)$ & $9.0(16.5)$ & $\begin{array}{l}0.109 \\
{[0.102 ; 0.116]}\end{array}$ \\
\hline Milk and dairy (mL and g) & $233.4(145.9)$ & $229.0(153.4)$ & $239.5(146.5)$ & $244.4(146.3)$ & $241.0(143)$ & $212.7(137.8)$ & $\begin{array}{l}-0.031 \\
{[-0.038 ;-0.024]}\end{array}$ \\
\hline Eggs (g) & $13.9(17.2)$ & $12.8(18.3)$ & $13.6(17.3)$ & $13.9(16.6)$ & $14.3(16.6)$ & $14.8(16.9)$ & $\begin{array}{l}0.038 \\
{[0.032 ; 0.045]}\end{array}$ \\
\hline Fish and seafood $(\mathrm{g})$ & $38.6(35.7)$ & $32.7(36.5)$ & $37.2(35.5)$ & $39.7(35.1)$ & $41.5(35.3)$ & $41.9(35.3)$ & $\begin{array}{l}0.086 \\
{[0.079 ; 0.093]}\end{array}$ \\
\hline Meat (g) & $69.4(44.4)$ & $83.5(50.2)$ & $73.8(44.3)$ & $70.0(41.6)$ & $65.4(40.3)$ & $54.3(39.2)$ & $\begin{array}{l}-0.227 \\
{[-0.233 ;-0.22]}\end{array}$ \\
\hline Processed meat/fish (g) & $34(28.1)$ & $55.6(33.9)$ & $40.3(27.8)$ & $31.9(23.4)$ & $25.0(19.5)$ & $17.2(15.4)$ & $\begin{array}{l}-0.467 \\
{[-0.472 ;} \\
0.462]\end{array}$ \\
\hline Fatty, sweet or salty food (g) & $102.6(50.5)$ & $105.5(58.8)$ & $106.7(53)$ & $105.5(48.9)$ & $101.5(46.1)$ & $93.8(43.2)$ & $\begin{array}{l}-0.074 \\
{[-0.081 ;-0.067]}\end{array}$ \\
\hline Non-oil fats (g) & $61.6(48.1)$ & $56.2(47.3)$ & $60.5(46.9)$ & $63.0(47.9)$ & $64.5(48.4)$ & $63.7(49.7)$ & $\begin{array}{l}0.052 \\
{[0.045 ; 0.059]}\end{array}$ \\
\hline Non-olive oil (g) & $4.5(5.3)$ & $5.0(6)$ & $4.5(5.2)$ & $4.4(4.9)$ & $4.3(4.9)$ & $4.5(5.3)$ & $\begin{array}{l}-0.032 \\
{[-0.039 ;-0.025]}\end{array}$ \\
\hline Olive oil (g) & $4.5(5.7)$ & $2.8(5)$ & $3.8(5.4)$ & $4.3(5.3)$ & $5.0(5.6)$ & $6.4(6.6)$ & $\begin{array}{l}0.21 \\
{[0.203 ; 0.217]}\end{array}$ \\
\hline Alcoholic drinks (mL) & $96.8(135.6)$ & $167.9(192.6)$ & $109.7(141)$ & $88.2(113.5)$ & $68.7(90.8)$ & $49.1(73.7)$ & $\begin{array}{l}-0.312 \\
{[-0.319} \\
0.306]\end{array}$ \\
\hline Unsweetened drinks (mL) & $1113.2(516.5)$ & $1029.4(531.8)$ & $1082.6(515.4)$ & $1110.9(501.3)$ & $1142.7(502.6)$ & $1201.3(515)$ & $\begin{array}{l}0.112 \\
{[0.105 ; 0.119]}\end{array}$ \\
\hline Sweetened drinks $(\mathrm{mL})$ & $41.5(89.3)$ & $77.2(149.3)$ & $44.8(85.6)$ & $34.4(64)$ & $28.4(51.9)$ & $22.7(39.4)$ & $\begin{array}{l}-0.223 \\
{[-0.229} \\
0.216]\end{array}$ \\
\hline
\end{tabular}

$\overline{{ }^{a}}$ Values are given per day, as mean (standard deviation), adjusted for energy intake and sex using the residual method, except for the organic score.

b Pearson's correlation coefficients with 95\% confidence intervals. All were significantly different from $0(\mathrm{p}<0.001)$. Absolute values $>0.2$ are written in bold. 
Supplemental Table 2 - Prospective association between the PNNS-GS2 and the risk of breast cancer depending on menopausal status, NutriNet-Santé study a

\begin{tabular}{|c|c|c|c|c|c|c|}
\hline & $\mathrm{T} 1$ & $\mathrm{~T} 2$ & T3 & $1 \mathrm{pt}$ & $1 \mathrm{SD}$ & $\mathrm{p}^{\mathrm{b}}$ \\
\hline \multicolumn{7}{|c|}{ Breast (premenopausal) } \\
\hline $\mathrm{n}$ & 14116 & 14077 & 14078 & 42271 & 42271 & \\
\hline Events & 82 & 102 & 97 & 281 & 281 & \\
\hline Person-years & 284405 & 260440 & 237616 & 782462 & 782462 & \\
\hline $\mathrm{HR}_{\mathrm{m} 2}{ }^{\mathrm{c}}$ & 1 & $1.24[0.91-1.68]$ & $1.32[0.95-1.85]$ & $1.05[1.00-1.10]$ & $1.17[1.01-1.35]$ & 0.03 \\
\hline \multicolumn{7}{|c|}{ Breast (postmenopausal) } \\
\hline $\mathrm{n}$ & 7845 & 7852 & 7838 & 23535 & 23535 & \\
\hline Events & 184 & 134 & 159 & 477 & 477 & \\
\hline Person-years & 89683 & 97372 & 101252 & 288307 & 288307 & \\
\hline $\mathrm{HR}_{\mathrm{m} 2}{ }^{\mathrm{c}}$ & 1 & $0.72[0.57-0.91]$ & $0.84[0.65-1.07]$ & $0.96[0.92-0.99]$ & $0.88[0.79-0.98]$ & 0.02 \\
\hline
\end{tabular}

${ }^{a}$ Bold value are significant for alpha at $5 \%$.

${ }^{\mathrm{b}}$ p-values are drawn from a Wald test for the PNNS-SG2 in continuous, which effect is presented for 1 point and for 1 standard deviation. As log-linearity hypothesis of Cox model was not fully satisfying on these outcomes, results should be treated with caution.

${ }^{\mathrm{c}}$ model $\mathrm{m} 2$ is adjusted on sex, energy intake without alcohol, ethanol intake, number of completed $24 \mathrm{~h}$ dietary records, height, season of inclusion, physical activity, occupation, smoking status, educational level, monthly income, cohabiting status, baseline BMI, menopausal status in women, hormonal treatment for menopause in menopaused women and oral contraception in nonmenopaused women, parental history of cancer and number of children. 
Supplemental Table 3 - Prospective association between PNNS-GS2 and risk of cancer of all sites except colorectal, NutriNet-Santé study a

\begin{tabular}{|c|c|c|c|c|c|c|c|}
\hline & Q1 & Q2 & Q3 & Q4 & Q5 & $1 \mathrm{pt}$ & $\mathrm{pval}^{\mathrm{b}}$ \\
\hline \multicolumn{8}{|l|}{$\begin{array}{l}\text { Cancer } \\
\text { (except colorectal) }\end{array}$} \\
\hline $\mathrm{n}$ & 15,174 & 15,115 & 15,151 & 15,121 & 15,073 & 75,634 & \\
\hline Events & 420 & 459 & 501 & 521 & 469 & 2370 & \\
\hline Person-years & 88,636 & 90,418 & 91,493 & 91,770 & 91,964 & 454,281 & \\
\hline $\mathrm{HR}_{\mathrm{m} 0} \mathrm{c}$ & 1 & $0.94[0.82-1.07]$ & $0.94[0.82-1.07]$ & $0.90[0.79-1.03]$ & $0.74[0.65-0.85]$ & $0.97[0.96-0.98]$ & $<0.0001$ \\
\hline $\mathrm{HR}_{\mathrm{m} 1}{ }^{\mathrm{d}}$ & 1 & $0.97[0.84-1.11]$ & $0.98[0.85-1.13]$ & $0.96[0.83-1.11]$ & $0.80[0.69-0.94]$ & $0.97[0.96-0.99]$ & $<0.0001$ \\
\hline $\mathrm{HR}_{\mathrm{m} 2}{ }^{\mathrm{e}}$ & 1 & $0.98[0.85-1.12]$ & $1.00[0.87-1.15]$ & $0.99[0.85-1.14]$ & $0.83[0.71-0.98]$ & $0.98[0.96-0.99]$ & 0.0009 \\
\hline
\end{tabular}

${ }^{a}$ For each model, 3 Cox regressions were fitted: one with PNNS-GS2 in quintiles, one with PNNS-GS2 for 1 point and one with PNNS-GS2 for $1 \mathrm{SD}$. Bold values are significant for alpha at $5 \%$.

${ }^{\mathrm{b}} \mathrm{p}$-values are drawn from a Wald test for the PNNS-SG2 in continuous, which effect is presented for 1 point and for 1 standard deviation.

${ }^{\mathrm{c}} \mathrm{m} 0$ is the base model, adjusted only for sex (and age as time-scale).

${ }^{\mathrm{d}} \mathrm{m} 1$ is further adjusted for energy intake without alcohol, ethanol intake, number of completed $24 \mathrm{~h}$ dietary records, height, season of inclusion, physical activity, occupation, smoking status, educational level, monthly income, cohabiting status, menopausal status in women, hormonal treatment for menopause in menopaused women and oral contraception in non-menopaused women, parental history (for cancer and CVD only) and number of children (for cancer and in women only).

${ }^{\mathrm{e}} \mathrm{m} 2$ is the principal model, further adjusted for baseline BMI.

${ }^{\mathrm{f}} \mathrm{m} 3$ is a complementary model for CVD, further adjusted for baseline hypertension status and dyslipidemia status. 
Supplemental Table 4 - Prospective association between the PNNS-GS2 and the risk of non-accidental mortality (for participants aged 35+), all-sites cancer and cardiovascular diseases without considering early cases (time $<2$ years), NutriNet-Santé study ${ }^{\text {a }}$

\begin{tabular}{|c|c|c|c|c|c|c|c|}
\hline & Q1 & Q2 & Q3 & Q4 & Q5 & $1 \mathrm{pt}$ & $\mathrm{p}^{\mathrm{b}}$ \\
\hline \multicolumn{8}{|l|}{ Mortality } \\
\hline $\mathrm{n}$ & 13,177 & 13,152 & 13,194 & 13,127 & 13,098 & 65,748 & \\
\hline Events & 122 & 136 & 103 & 126 & 128 & 615 & \\
\hline Person-years & 84,399 & 85,650 & 85,424 & 85,199 & 84,704 & 425,377 & \\
\hline $\mathrm{HR}_{\mathrm{m} 0}^{\mathrm{c}}$ & 1 & $0.94[0.74-1.20]$ & $0.67[0.51-0.87]$ & $0.75[0.59-0.97]$ & $0.71[0.55-0.91]$ & $0.96[0.93-0.98]$ & 0.0004 \\
\hline $\mathrm{HR}_{\mathrm{m} 1}^{\mathrm{d}}$ & 1 & $0.97[0.76-1.25]$ & $0.69[0.52-0.92]$ & $0.78[0.59-1.02]$ & $0.73[0.55-0.99]$ & $0.96[0.93-0.99]$ & 0.005 \\
\hline $\mathrm{HR}_{\mathrm{m} 2}{ }^{\mathrm{e}}$ & 1 & $0.99[0.77-1.28]$ & $0.72[0.54-0.96]$ & $0.81[0.61-1.08]$ & $0.78[0.58-1.05]$ & $0.96[0.94-0.99]$ & 0.017 \\
\hline \multicolumn{8}{|l|}{ Cancer } \\
\hline $\mathrm{n}$ & 15,174 & 15,115 & 15,151 & 15,121 & 15,073 & 75,634 & \\
\hline Events & 327 & 368 & 390 & 394 & 356 & 1835 & \\
\hline Person-years & 89,091 & 90,950 & 92,029 & 92,283 & 92,526 & 456,878 & \\
\hline $\mathrm{HR}_{\mathrm{m} 0} \mathrm{c}$ & 1 & $0.95[0.82-1.10]$ & $0.92[0.79-1.06]$ & $0.85[0.73-0.98]$ & $0.69[0.60-0.81]$ & $0.96[0.94-0.97]$ & $<0.0001$ \\
\hline $\mathrm{HR}_{\mathrm{ml}}^{\mathrm{d}}$ & 1 & $0.98[0.84-1.15]$ & $0.96[0.82-1.13]$ & $0.91[0.77-1.07]$ & $0.74[0.62-0.89]$ & $0.96[0.95-0.98]$ & $<0.0001$ \\
\hline $\mathrm{HR}_{\mathrm{m} 2} \mathrm{e}^{\mathrm{e}}$ & 1 & $1.00[0.85-1.16]$ & 0.98 [0.84-1.15] & $0.93[0.79-1.10]$ & $0.77[0.65-0.92]$ & $0.97[0.95-0.98]$ & 0.0001 \\
\hline \multicolumn{8}{|l|}{ CVD } \\
\hline $\mathrm{n}$ & 16,105 & 16,129 & 15,972 & 16,146 & 15,917 & 80,269 & \\
\hline Events & 135 & 136 & 145 & 136 & 161 & 713 & \\
\hline Person-years & 95,637 & 98,443 & 98,638 & 99,882 & 98,869 & 491,469 & \\
\hline $\mathrm{HR}_{\mathrm{m} 0} \mathrm{c}$ & 1 & $0.83[0.65-1.05]$ & $0.80[0.63-1.01]$ & $0.68[0.54-0.87]$ & $0.74[0.59-0.93]$ & $0.97[0.95-0.99]$ & 0.004 \\
\hline $\mathrm{HR}_{\mathrm{ml}}{ }^{\mathrm{d}}$ & 1 & $0.81[0.63-1.03]$ & $0.74[0.58-0.96]$ & $0.63[0.48-0.82]$ & $0.66[0.50-0.86]$ & $0.96[0.93-0.98]$ & 0.001 \\
\hline $\mathrm{HR}_{\mathrm{m} 2}{ }^{\mathrm{e}}$ & 1 & $0.82[0.64-1.04]$ & $0.77[0.59-0.99]$ & $0.65[0.50-0.85]$ & $0.70[0.53-0.92]$ & $0.96[0.94-0.99]$ & 0.007 \\
\hline $\mathrm{HR}_{\mathrm{m} 3}{ }^{\mathrm{f}}$ & 1 & $0.81[0.64-1.04]$ & $0.78[0.60-1.00]$ & $0.66[0.51-0.87]$ & $0.71[0.54-0.95]$ & $0.97[0.94-0.99]$ & 0.013 \\
\hline
\end{tabular}

${ }^{a}$ Bold values are significant for alpha at $5 \%$.

${ }^{\mathrm{b}} \mathrm{p}$-values are computed using a Wald test for the PNNS-SG2 in continuous, which effect is presented for 1 point.

${ }^{\mathrm{c}} \mathrm{m} 0$ is the base model, adjusted only on sex.

${ }^{\mathrm{d}} \mathrm{m} 1$ is further adjusted on energy intake without alcohol, ethanol intake, number of completed 24h dietary records, height, season of inclusion, physical activity, occupation, smoking status, educational level, monthly income, cohabiting status, menopausal status in women, hormonal treatment for menopause in menopaused women and oral contraception in non-menopaused women, parental history (for cancer and CVD only) and number of children (for cancer and in women only).

${ }^{\mathrm{e}} \mathrm{m} 2$ is the principal model, further adjusted on BMI.

${ }^{\mathrm{f}} \mathrm{m} 3$ is a complementary model for CVD, further adjusted on baseline hypertension status and dyslipidemia status. 